\title{
O Mito da Estabilidade da Configuração Eletrónica de Gás Nobre
}

Carlos Corrêa

\author{
The Myth of Stability of the Electronic \\ Configuration of Noble Gas. The idea that \\ atoms tend to lose or accept electrons in order \\ to get the noble gas electronic configuration is \\ a myth and must be faced as a mnemonic.
}

\begin{abstract}
A ideia repetida de que os átomos tendem a perder ou ganhar eletrões de modo a adquirir a configuração eletrónica do gás nobre mais próximo não é correta e deve ser encarada como uma mnemónica.
\end{abstract}

Os manuais escolares, livros de texto e programas oficiais repetidamente propagam a ideia errada de que os átomos tendem a perder ou ganhar eletrões de modo a adquirir a configuração eletrónica do gás nobre mais próximo. Assim, a estabilidade dessa configuração eletrónica seria uma espécie de força motriz de origem um tanto metafísica para a formação dos compostos (Figura 1).

$$
\begin{aligned}
& \text { Figura } 1 \text { - Os átomos de sódio e oxigénio } \\
& \text { adquirem configuração eletrónica de gás nobre. }
\end{aligned}
$$
de gás nobre

Será que os átomos de sódio e de oxigénio tendem realmente a adquirir as configurações eletrónicas de gás nobre? Os valores da energia de ionização do sódio e da segunda afinidade eletrónica do oxigénio mostram que nenhum deles fica mais estável se se transformar em ião, $\mathrm{Na}^{+}$ou $\mathrm{O}^{2-}$ (Figura 2). 0 oxigénio tende a captar um só eletrão, mas a passagem à configuração eletrónica de gás nobre não é nada favorável, o mesmo sucedendo com o nitrogénio. Mesmo os metais alcalinos, como é o caso do sódio, têm mais tendência a ganhar do que a perder eletrões (o que lhes conferiria configuração eletrónica de gás nobre).
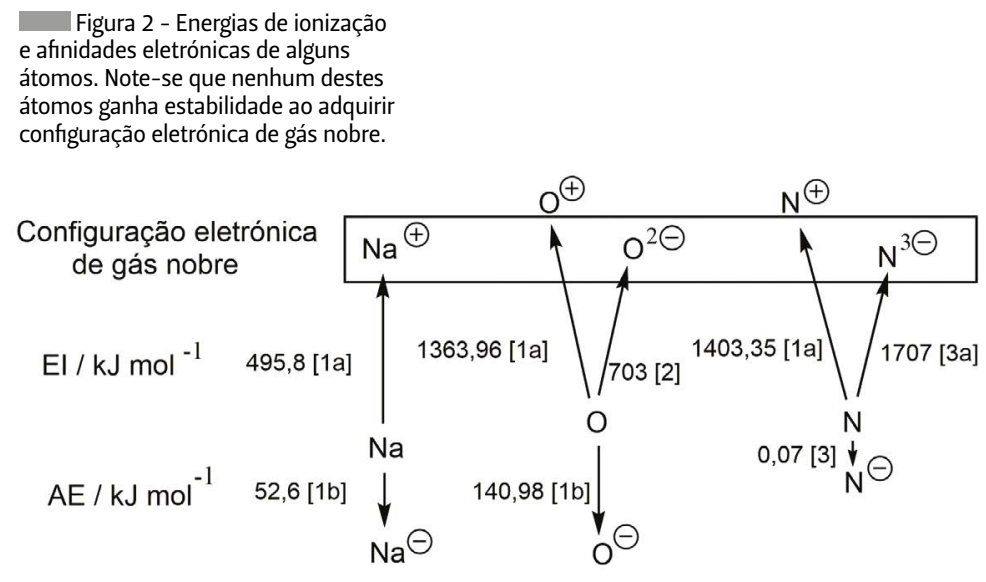

Qual a energia posta em jogo quando dois átomos de sódio reagem com um átomo de oxigénio? Podemos calcular essa energia a partir da energia de ionização do sódio e da 2. ${ }^{a}$ afinidade eletrónica do oxigénio (Figura 3) e verificar que a transformação é endotérmica, ou seja, que o sistema não ganha estabilidade.

Figura 3 - Para que um átomo de oxigénio receba dois eletrões de dois átomos de sódio, originando dois iões com configuração eletrónica de gás nobre, é preciso fornecer energia ao sistema. Nenhuma das partículas adquiriu maior estabilidade.

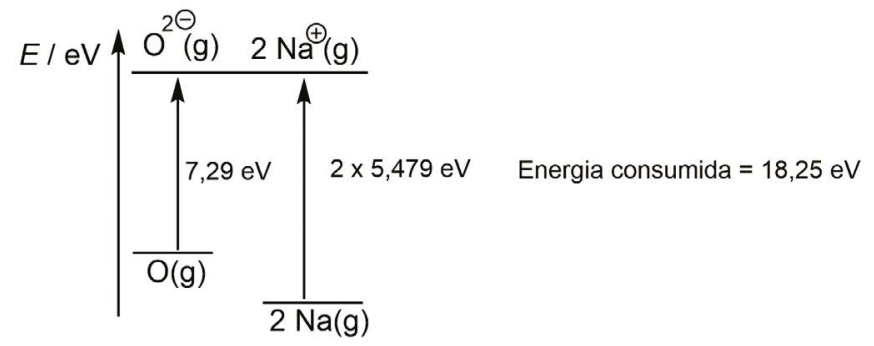


No entanto, se partirmos de uma mole de oxigénio atómico e duas moles de átomos de sódio para formar uma mole de $\mathrm{Na}_{2} \mathrm{O}$ cristalino, o sistema já liberta energia [1c].

$\mathrm{O}(\mathrm{g})+2 \mathrm{Na}(\mathrm{g}) \rightarrow \mathrm{O}^{2-}(\mathrm{g})+2 \mathrm{Na}^{+}(\mathrm{g}) \rightarrow \mathrm{Na}_{2} \mathrm{O}(\mathrm{s}) \quad \Delta H=-786 \mathrm{~kJ} / \mathrm{mol}$

Embora a formação dos iões seja endotérmica (cerca de $703 \mathrm{~kJ} / \mathrm{mol}+2 \times 496 \mathrm{~kJ} / \mathrm{mol}=1695 \mathrm{~kJ} / \mathrm{mol}$ ), a energia libertada pela aproximação dos iões de sinal contrário para formar a rede cristalina (energia reticular, - $2481 \mathrm{~kJ} / \mathrm{mol}$ [1c]), compensa fortemente a energia consumida na ionização (1695 kJ/mol - 2481 $\mathrm{kJ} / \mathrm{mol}=-786 \mathrm{~kJ} / \mathrm{mol}$ ). A força motriz da reação não foi a formação de iões com configuração eletrónica de gás nobre, mas as atrações eletrostáticas entre os catiões e aniões no cristal.

Quanto à ligação entre dois átomos de oxigénio para formar uma molécula (Figura 1), a verdade é que nenhum dos átomos ganha estabilidade ao adquirir a configuração eletrónica de gás nobre, pois para formar $\mathrm{O}^{2-}$ é preciso fornecer ao átomo 7,29 eV. A razão da formação da molécula é o aumento da densidade eletrónica na zona internuclear, passando os núcleos a serem atraídos para essa nuvem com carga elétrica negativa.

Os valores das afinidades eletrónicas do ião $\mathrm{N}^{2-}$ mostram, também, que os átomos de nitrogénio não têm qualquer tendência a adquirir a configuração eletrónica de gás nobre, pois a transformação $\mathrm{N} \rightarrow$ $\mathrm{N}^{3-}$ é bastante endotérmica:
$\mathrm{N}(\mathrm{g}) \rightarrow \mathrm{N}^{3-}(\mathrm{g})$
$\Delta H=+1707 \mathrm{~kJ} / \mathrm{mol}$

Os átomos de nitrogénio não se ligam para adquirirem a configuração eletrónica de gás nobre (isso seria altamente endotérmico), mas devido à elevada densidade eletrónica internuclear quando se ligam por covalência.

Os valores das energias de segunda ionização dos metais alcalinoterrosos [1d] mostram igualmente que estes metais não têm qualquer tendência a adquirir a configuração eletrónica de gás nobre:

$\begin{array}{ll}\mathrm{Be}^{+}(\mathrm{g}) \rightarrow \mathrm{Be}^{2+}\left(\mathrm{g}^{\prime}\right) & \Delta H=+1757 \mathrm{~kJ} / \mathrm{mol} \\ \mathrm{Mg}^{+}(\mathrm{g}) \rightarrow \mathrm{Mg}^{2+}(\mathrm{g}) & \Delta H=+1451 \mathrm{~kJ} / \mathrm{mol} \\ \mathrm{Ca}^{+}(\mathrm{g}) \rightarrow \mathrm{Ca}^{2+}(\mathrm{g}) & \Delta H=+1145 \mathrm{~kJ} / \mathrm{mol}\end{array}$

A maior vulgaridade dos catiões alcalinos em relação aos respetivos aniões deve-se a facto de haver átomos na Natureza com maior apetência eletrónica, capazes de remover eletrões dos átomos com mais baixa energia de ionização (caso dos metais alcalinos, cuja carga nuclear efetiva é diminuída pelos eletrões das orbitais interiores). Em contraste, átomos como o oxigénio e o flúor, com carga nuclear elevada e pouca blindagem nuclear, têm elevada tendência para remover eletrões de outros átomos. No entanto, a remoção de mais eletrões para adquirir configuração eletrónica de gás nobre é desfavorável pelo aumento das repulsões eletrónicas. Isso só será possível se aumentar a carga nuclear.

Os gases nobres, possuindo a maior carga nuclear do respetivo período e a mesma blindagem nuclear, apresentam assim elevada energia de ionização. Não têm praticamente afinidade eletrónica porque o eletrão teria de ir ocupar a camada $n+1$, com todos os eletrões do cerne a efetuar uma apreciável blindagem nuclear. Daqui resulta a sua estabilidade.

Os exemplos apresentados demonstram claramente que é errado considerar a configuração eletrónica de gás nobre como um fator de estabilidade e motor da formação dos agregados de átomos, pois há outros fatores importantes a considerar (a carga nuclear, a carga nuclear efetiva, a grandeza da carga, o tamanho de cada ião e o estado, gasoso ou cristalino).

Assim, configuração eletrónica de gás nobre deve ser encarada como uma mnemónica para os alunos preverem a carga dos aniões e catiões, mas não como a causa da estabilidade dessas partículas. É mais uma consequência da presença de outros fatores.

\section{Referências}

[1] W. M. Haynes, CRC Handbook of Chemistry and Physics, $97^{\text {th }}$ Edition, CRC Press, 2016. a) 10-214; b) 10-147; c) 12-17; d) 10-204. As energias em $\mathrm{kJ} \mathrm{mol}^{-1}$ foram obtidas a partir dos valores em eV, multiplicados por $96,487 \mathrm{~kJ} \mathrm{~mol}^{-1} / \mathrm{eV}$.

[2] Calculado a partir das afinidades eletrónicas de 0 e 0-. chemguide.co.uk/ atoms/properties/eas.html\#: : :text=The\%20second\%20 electron\%20 affinity\%20is,easily\%20seen\%20in\%20symbol\%20terms (acedido em 17/08/2020).

[3] en.wikipedia.org/wiki/Electron_affinity_(data_page). a) Calculado a partir da afinidade eletrónica de N, N- e $\mathrm{N}^{2-}$ (acedido em 17/08/2020).

\section{$>$}

\section{Carlos Corrêa}

É Professor Emérito do Departamento de Química e Bioquímica (DQB) da Faculdade de Ciências da Universidade do Porto (FCUP). Frequentou a FCUP e a Faculdade de Engenharia da Universidade do Porto onde se licenciou em Engenharia Química Industrial. Doutorou-se na Universidade de Oxford e na Universidade do Porto em radicais livres de compostos de enxofre. Foi Professor Catedrático no DQB da FCUP, onde desenvolveu atividade de investigação e docência na área da Química Orgânica, tendo-se jubilado em 2006. É autor de vários artigos científicos publicados em revistas internacionais e de manuais escolares para a disciplina de Física e Química lecionada no ensino básico e secundário. ccorrea@fc.up.pt Carlos Corrêa_FCUP 